\title{
ATRIBUTOS BIOLÓGICOS DO SOLO EM SISTEMA DE INTEGRAÇÃO LAVOURA-PECUÁRIA- FLORESTA, NA REGIÃO AMAZÔNICA
}

\author{
Benhur da Silva Oliveira ${ }^{1}$, Marco Antonio Camillo de Carvalho ${ }^{2}$, Anderson Lange ${ }^{3}$, Flavio Jesus Wruck ${ }^{4}$, Rivanildo \\ Dallacort ${ }^{5}$
}

\section{RESUMO}

As propriedades biológicas do solo são importantes ferramentas a serem utilizadas no monitoramento das alterações ambientais no solo decorrentes do uso agrícola. Nesta perspectiva, o objetivo do trabalho foi avaliar os atributos biológicos do solo em área submetida ao sistema de integração Lavoura-Pecuária-Floresta. Essa pesquisa foi realizada em uma Unidade de Referência Tecnológica (URT) de integração Lavoura-Pecuária-Floresta (iLPF) implantada em 20 hectares na Fazenda Gamada, no município de Nova Canaã do Norte (MT). Caracterizados pelas espécies florestais implantadas, os tratamentos foram constituídos pela combinação das espécies: Pinho cuiabano (Schizolobium amazonicum), Pau-balsa (Ochroma pyramidale), Teca (Tectona grandis) e Eucalipto (Eucalyptus urograndis), sendo estas, implantadas em linha tripla, intercalada por faixas de 20 metros de largura, destinadas para implantação das atividades agrícola e pecuária. Foram analisadas também solos sob vegetação nativa e pastagem conduzida por meio de sistema convencional, localizadas em área adjacente à URT e que apresentam a mesma classe de solo (Latossolo Vermelho Amarelo distroférrico). O delineamento utilizado foi o inteiramente casualizado, em arranjo fatorial (6 x 2), sendo seis tratamentos e dois locais de avaliações (entre os renques florestais e na faixa de pastagem), com três repetições. As seguintes características foram analisadas: Respiração Basal do Solo, Carbono Orgânico, e teor de Matéria Orgânica. O tratamento Vegetação nativa apresentou o maior valor de respiração basal do solo, 2,54 mg de $\mathrm{C}-\mathrm{CO}_{2}$ por kg de solo por hora. Entre os tratamentos sob os sistemas integração lavoura-pecuária-floresta o tratamento Pau-balsa entre os renques florestais foi o que apresentou as melhores médias para as características analisadas.

Palavras-chaves: Agrossilvipastoril, iLPF, Sistemas integrados, Florestais

\section{ABSTRACT}

\section{BIOLOGICAL ATTRIBUTES OF SOIL IN INTEGRATED CROP-LIVESTOCK-FOREST SYSTEMS IN THE AMAZON REGION}

The biological properties of soil are important indicators for monitoring environmental changes in soil resulting from agricultural use. The objective of this study was to evaluate the biological attributes of soil in an integrated crop-livestock-forest (iLPF) area. The study was conducted in an iLPF reference technology unit (RTU) planted on 20 acres of the Gamada farm in Nova Canaã do Norte MT, Brazil. According to the specific combination of forest species planted, different uses were designated. The species planted included Pinho cuiabano (Schizolobium amazonicum), Pau-balsa (Ochroma pyramidale), Teak (Tectona grandis), and Eucalyptus (Eucalyptus urograndis). They were planted in triple lines, interspersed with lanes 20 feet wide designed for agricultural and livestock activities. We also analyzed the soils under native vegetation and a pasture utilized in a conventional agricultural system, both located in an area adjacent to RTU and having the same type of soil (Typic dystrophic). The experimental design was completely randomized in a factorial arrangement $(6 \times 2)$, with six use types, two local ratings (rows between forest and grassland range), and three replications. The following characteristics were analyzed: basal respiration of the soil, organic carbon, and organic matter content. Native vegetation soil had the highest amount of soil basal respiration, $2.54 \mathrm{mg} \mathrm{C}-\mathrm{CO}_{2} .2,54 \mathrm{mg}$ de C-CO2 per $\mathrm{kg}$ the soil per hour Among the uses in the iLPF systems, the soil characteristics of the Pau-balsa rows forest yielded the best results.

Keywords: Agrossilvipastoril, iLPF, Integrated systems, Forest

\section{Recebido para publicação em 04/07/2014. Aprovado em 19/08/2015.}

1 - Engenheiro Florestal, Professor da UNEMAT/Tangará da Serra - MT, e-mail: benhur.florestal@hotmail.com

2 - Agrônomo, Professor Adjunto da UNEMAT/Alta Floresta - MT, e-mail: marcocarvalho@unemat.br

3 - Agrônomo, Professor Adjunto da UFMT/Sinop-MT, e-mail: lange@cpd.ufmt.br

4 - Agrônomo, Pesquisador da EMBRAPA/Sinop-MT, e-mail: flavio.wruck@embrapa.br

5 - Engenheiro Agrícola, Professor Adjunto da UNEMAT/Tangará da Serra - MT, e-mail: rivanildo@unemat.br

\section{REVENG}




\section{INTRODUÇÃO}

A pressão social e econômica para produção de alimentos nos últimos anos, conjuntamente com a exploração inadequada e não planejada dos recursos naturais, tem provocado a degradação de extensas áreas e transformações impróprias de ambientes naturais em áreas agrícolas (FONSECA et al., 2007). Com isso, o principal elemento impactado é o solo, o qual faz parte diretamente da sustentabilidade dos ecossistemas naturais e influencia diretamente a produtividade nos sistemas agrícolas (COOPER, 2008).

Para Neves et al. (2009) e Silva et al. (2010), a preocupação com a avaliação da qualidade do solo merece atenção, pois a quantificação das alterações em seus atributos, decorrentes da intensificação de seu uso e manejo, serve para monitorar a produtividade dos solos e a conservação dos recursos naturais. Araújo e Monteiro (2007) destacam as propriedades biológicas e bioquímicas do solo como importantes indicadores a serem utilizados no monitoramento das alterações ambientais decorrentes do uso agrícola, sendo ferramentas para orientar o planejamento e avaliar práticas de manejo utilizadas.

Dentre as propriedades biológicas, pode-se destacar a respiração basal, ou atividade microbiana, que, assim como outros processos metabólicos, é dependente do estado fisiológico da célula microbiana e é influenciada por diversos fatores do solo, como: conteúdo de água, temperatura, estrutura, disponibilidade de nutrientes, textura, relação $\mathrm{C} / \mathrm{N}$ e presença de resíduos orgânicos (SILVA et al., 2010).

A microbiota do solo é a principal responsável pela decomposição dos resíduos orgânicos, pela ciclagem de nutrientes e pelo fluxo de energia dentro do solo, exercendo influência, tanto na transformação da matéria orgânica quanto na estocagem do carbono e nutrientes minerais (JENKINSON; LADD, 1981).

Com o crescente interesse em aspectos relacionados com o funcionamento biológico do solo sob sistemas naturais e agrícolas, há necessidade de maiores estudos, principalmente os de forma contínua (monitoramento) sobre o impacto dos diferentes sistemas de manejo na biomassa e atividade microbiana dos solos (PEREIRA et al., 2007), pois, como abordado por Araújo e Monteiro (2007), a biomassa e a atividade microbiana têm sido apontadas como indicadores adequados de alterações provocadas ao equilíbrio do solo.

Neste contexto, o presente trabalho teve como objetivo avaliar a atividade microbiana (respiração basal) do solo em áreas submetidas a sistema de integração lavoura-pecuária-floresta, implantada com quatro espécies florestais e comparar com solos de área com vegetação nativa e pastagem implantada e conduzida pelo sistema convencional no mesmo local.

\section{MATERIAL E MÉTODOS}

O presente trabalho foi realizado em uma Unidade de Referência Tecnológica (URT) integração lavoura-pecuária-floresta (iLPF) implantada em 20 hectares na Fazenda Gamada $\left(10^{\circ} 24^{\prime} 10^{\prime \prime} \mathrm{S}, 55^{\circ} 43^{\prime} 22^{\prime}\right.$ ' W), município de Nova Canaã do Norte, localizado no extremo norte do Estado de Mato Grosso.

Segundo a classificação de Köppen, a região apresenta clima tipo Awi (tropical chuvoso) com nítida estação seca durante os meses de maio a agosto. A temperatura média anual varia entre $20^{\circ} \mathrm{C}$ e $38^{\circ} \mathrm{C}$, com média de $26^{\circ} \mathrm{C}$ (FERREIRA, 2001). A média anual de precipitação pluviométrica da área nos últimos seis anos é de $2.175 \mathrm{~mm}$. O solo da área experimental é classificado como Latossolo Vermelho Amarelo distroférrico de textura média (EMBRAPA, 2013). Dois meses antes da instalação do experimento, o solo foi amostrado na profundidade de $0-0,20 \mathrm{~m}$, o qual apresentava as características químicas confrome apresentado no Quadro 1.

A área de 20 hectares foi subdividida em quatros tratamentos de 5 hectares cada, os quais foram caracterizados e diferenciados de acordo com a espécie florestal implantada. A área com vegetação nativa e pastagem implantada, conduzida pelo sistema convencional, utilizadas como parâmetro de comparação, trata-se de duas áreas adjacentes da área experimental, que apresentam a mesma classe de solo e condições de declividade.

Em 1998, a área da URT - iLPF teve sua vegetação de Floresta Ombrófila desmatada 
Quadro 1. Análise química do solo da área experimental, na camada de 0,0-0,2 m de profundidade

\begin{tabular}{|c|c|c|c|c|c|c|c|c|c|}
\hline \multirow{2}{*}{$\begin{array}{c}\mathrm{pH} \\
\left(\mathrm{H}_{2} \mathrm{O}\right)\end{array}$} & \multirow{2}{*}{$\begin{array}{c}\mathrm{MO} \\
\mathrm{g} \mathrm{dm}^{-3}\end{array}$} & $\mathrm{Ca}$ & $\mathrm{Mg}$ & $\mathrm{Al}$ & $\mathrm{H}$ & $\mathrm{P}$ & K & \multirow{2}{*}{$\begin{array}{c}\mathrm{T} \\
\text { cmolc dm }\end{array}$} & \multirow[t]{2}{*}{$\mathrm{V} \%$} \\
\hline & & ----- & $-----c$ & $\mathrm{Im}^{-3}-$ & ----- & \multicolumn{2}{|c|}{-----mg dm${ }^{-3}$} & & \\
\hline 5,7 & 17 & 1,56 & 0,44 & 0 & 3,2 & 2,5 & 111 & 5,48 & 41,6 \\
\hline
\end{tabular}

Extratores: P e K: Mehlich; Ca, Mg e Al: KCl 1N; H + Al: SMP.

Quadro 2. Caracterização da área experimental, com a relação dos tratamentos, número de amostragens em cada local de avaliação e arranjo de implantação

\begin{tabular}{cccc}
\hline \multirow{2}{*}{ Tratamento } & \multicolumn{2}{c}{ Locais de avaliação } & Espaçamento \\
\cline { 2 - 3 } & $\begin{array}{c}\text { Floresta } \\
\text { No de amostragens }\end{array}$ & \\
\hline Eucalipto Clone h13 (E. grandis $x$ E.urophylla) & 9 & 9 & $20 \times 3 \times 2$ \\
Teca (Tectona grandis L. f.) & 9 & 9 & $20 \times 3 \times 2$ \\
Pinho cuiabano (Schizolobium amazonicum Huber ex Ducke) & 9 & 9 & $20 \times 3 \times 3$ \\
Pau-balsa (Ochroma pyramidale) & 9 & 9 & $20 \times 3 \times 3$ \\
Vegetação nativa & 9 & $* *$ & -- \\
Pastagem convencional (Brachiaria brizantha cv Marandú) & $* *$ & 9 & -- \\
\hline
\end{tabular}

** Não apresentam locais diferentes para avaliação.

para a implantação de pastagem com braquiarão (Brachiaria brizantha cv Marandu), a qual permaneceu por dois anos. Em seguida, a área foi utilizada para o cultivo de culturas anuais por seis anos consecutivos, sendo: dois anos cultivada com arroz e quatro anos com soja seguida de milho, como safrinha. Depois desse período, a lavoura foi substituída pela pastagem, novamente com braquiarão, a qual permaneceu na área por dois anos, até a implantação do experimento (20062008).

Em janeiro de 2009, no sulco central, foi realizado o plantio das mudas das espécies florestais Pinho Cuiabano (Schizolobium amazonicum), Pau-balsa (Ochroma pyramidale), Teca (Tectona grandis) e Eucalipto (Eucalyptus urograndis), todas em linha tripla, intercalada por faixas de 20 metros de largura destinadas para implantação das atividades agrícola e pecuária.

$\mathrm{O}$ delineamento utilizado foi o inteiramente casualizado, em arranjo fatorial $(6 \times 2)$, sendo seis tratamentos e dois locais de avaliações (entre os renques florestais e na faixa de pastagem) com três repetições. No Quadro 2, encontra-se a relação dos tratamentos, com a caracterização das amostragens e do tratamento. As amostragens do local de avaliação floresta foram realizadas na linha central dos renques triplo dos indivíduos florestais, já no local de avaliação pastagem foram realizadas as amostragens no centro da faixa.

Todas as amostragens foram realizadas de forma aleatória. No tratamento vegetação nativa, observou-se um distanciamento da borda, para que a mesma não interferisse nos resultados.

As amostragens foram realizadas em junho de 2012, na camada de 0 a $0,10 \mathrm{~m}$ de profundidade do solo, sendo essas acondicionadas em sacos plásticos protegidas da luz e mantidas em uma caixa térmica. Seguindo as recomendações de Silva et al. (2007), visando manter as amostras em condições mais próximas da quais foram coletadas em campo, as amostras foram encaminhadas no 
prazo máximo de 24 horas para o laboratório.

Para determinação da respiração basal do solo (RBS), foram adotados os procedimentos propostos por Silva et al. (2007), enquanto que para determinação do C-orgânico e matéria orgânica do solo foram adotados os procedimentos estabelecidos pelo Manual de Métodos de Análise de Solos - Embrapa (1997). Todas as análises foram realizadas no Laboratório de Solos e Análise Foliar da Universidade do Estado de Mato Groso UNEMAT, Campus de Alta Floresta.

Os dados obtidos foram submetidos à análise de variância e as médias foram comparadas pelo teste de Tukey $(\mathrm{p} \leq 0.05)$ utilizando o software estatístico Sisvar (FERREIRA, 2011).

\section{RESULTADOS E DISCUSSÃO}

Conforme apresentado no Quadro 3, observouse que para nenhuma das características avaliadas houve influência do local de avaliação. Foi observada diferença significância entre os usos e interação somente entre os fatores Uso x Local para a Respiração Basal do Solo (RBS). Para o teor de matéria orgânica do solo, não ocorreu diferença significativa entre os níveis dos fatores e também interação entre os mesmos.

Quadro 3. Valores de $\mathrm{F}$ e coeficiente de variação $(\mathrm{CV} \%)$ da Respiração Basal do Solo (RBS) em função de diferentes usos e locais. Nova Canaã do Norte - MT, (2012)

\begin{tabular}{cccc}
\hline Fonte de variação & RBS & C- orgânico & M.O \\
\hline Uso & $114,93^{* *}$ & $0,92^{\text {ns }}$ & $0,93^{\text {ns }}$ \\
Local & $3,60^{\text {ns }}$ & $0,70^{\text {ns }}$ & $0,71^{\text {ns }}$ \\
Uso x Local & $9,46^{* *}$ & $0,48^{\text {ns }}$ & $0,47^{\text {ns }}$ \\
\hline CV $(\%)$ & 12,41 & 27,16 & 27,06 \\
\hline
\end{tabular}

**- Significativo em nível de $1 \%$ de probabilidade

ns - Não significativo em nível de 5\% de probabilidade

Os resultados dos valores médios de RBS, Carbono Orgânico (C-orgânico), e teor de Matéria Orgânica (M.O), conforme apresentado no Quadro

Quadro 4. Valores médios de Respiração Basal do Solo (RBS), Carbono orgânico (C-orgânico) e teor de Matéria Orgânica do solo (M.O), em função de diferentes usos e locais de amostragem. Nova Canaã do Norte - MT, 2012

\begin{tabular}{cccc}
\hline Uso (U) & $\begin{array}{c}\mathrm{RBS} \\
\left(\mathrm{mg} \mathrm{de} \mathrm{C-CO} \cdot \mathrm{Kg}^{-1} \cdot\right. \\
\left.\text { solo.h }{ }^{-1}\right)\end{array}$ & $\begin{array}{c}\text { C-orgânico } \\
\left(\mathrm{g} . \mathrm{kg}^{-1} \cdot \mathrm{solo}\right)\end{array}$ & $\begin{array}{c}\mathrm{M} . \mathrm{O} \\
\left(\mathrm{g} . \mathrm{kg}^{-1} \cdot\right. \\
\text { solo })\end{array}$ \\
\hline Vegetação Nativa & 2,54 & 20,12 & 34,51 \\
Pastagem convencional (Brachiaria brizantha cv Marandú) & 0,85 & 13,96 & 24,04 \\
Eucalipto Clone h13 (E. grandis x E. urophylla) & 0,85 & 17,04 & 29,4 \\
Pau-balsa (Ochroma pyramidale) & 0,91 & 17,32 & 24,82 \\
Teca (Tectona grandis L. f.) & 0,85 & 15,12 & 26,07 \\
Pinho cuiabano (Schizolobium amazonicum Huber ex Ducke) & 0,52 & 13,33 & 26,42 \\
\hline DMS (Tukey 5\%) & 0,32 & 10,6 & 17,85 \\
\hline Local (L) & & & \\
Floresta & 1,14 & 17,22 & 29,71 \\
\hline Pastagem & 1,04 & 15,68 & 27,05 \\
\hline DMS (Tukey 5\%) & 0,12 & 3,95 & 6,82 \\
\hline
\end{tabular}

DMS: Diferença mínima significativa. 
4, demonstram o comportamento para o uso e locais de avaliações analisados neste trabalho.

Não foram observadas diferenças significativas no teor de C-orgânico e M.O em análise dos diferentes usos e locais de avaliação. Verificou-se que em todos os usos analisados havia acúmulo de material orgânico, resultante da contribuição do sistema de plantio direto e das folhas e galhos das espécies florestais nos sistemas integrados, assemelhando assim, as condições (valores) do uso vegetação nativa. Bayer et al. (2000), Ciotta et al. (2002) e Santos et al. (2009), abordam a eficiência dos sistemas integrados em acumular M.O e Carbono nas camadas mais próximas à superfície do solo, decorrente dos resíduos vegetais que permanecem sobre o solo.

O uso pastagem convencional também apresentou acúmulo de material orgânico, assim como de matéria orgânica sobre o solo, logo não se diferiu do teor de C-orgânico e matéria orgânica dos demais tratamentos. Braz et al. (2004) e Netto et al. (2009) caracterizam altos teores de matéria orgânica em solo sob pastagem convencional devido ao comportamento das gramíneas, dada sua eficiência de incorporação de matéria orgânica no solo, podendo alguns casos ser superior ao encontrados em área sob vegetação nativa.
Os valores muito próximos de C-orgânico, matéria orgânica e RBS entre os locais de avaliação podem estar associados aos benefícios proporcionados pelos sistemas integrados, os quais possibilitam a sinergia entre as atividades (agrícola/ pecuária/florestal), proporcionando a formação de serrapilheira pelas espécies florestais. Estes resultados corroboram com os observados por Melo e Resck (2003), que destacam a importância da ciclagem de nutrientes nos sistemas integrados. Benefícios da integração lavoura e pecuária também foram apontados por Macedo (2009) e Chioderoli et al. (2012), onde discutem que a ocorrência de melhoria das propriedades físicas e biológica do solo é devido à maior produção de palha.

$\mathrm{O}$ desdobramento da interação significativa (Uso x Locais) está apresentado no Quadro 5. Nota-se que o tratamento vegetação nativa apresentou maiores valores de RBS em ambos os locais. Ressalta-se que o valor do tratamento vegetação nativa e pastagem convencional foram duplicados para efeito de comparação com os demais tratamentos.

O tratamento vegetação nativa (Quadro 5) apresentou a maior média da taxa de respiração basal do solo, $2,54 \mathrm{mg}$ de C- $\mathrm{CO}_{2} \mathrm{~kg}^{-1} \mathrm{~h}^{-1}\left(\mathrm{C}-\mathrm{CO}_{2}\right.$ por $\mathrm{kg}$ de solo por hora), diferindo significativamente

Quadro 5. Desdobramento da interação significativa entre uso e locais de amostragem da Respiração Basal do Solo (RBS) em Nova Canaã do Norte-MT (2012)

\begin{tabular}{|c|c|c|}
\hline \multirow{2}{*}{ Uso } & \multicolumn{2}{|c|}{ Local } \\
\hline & Floresta & Pastagem \\
\hline & \multicolumn{2}{|c|}{$\mathrm{RBS}$ (mg de C- $\mathrm{CO}_{2} \cdot \mathrm{Kg}^{-1}$.solo.hora $\left.{ }^{-1}\right)$} \\
\hline Vegetação Nativa & 2,54 a $\mathrm{A}$ & $2,54 \mathrm{a} \mathrm{A}^{*}$ \\
\hline Pastagem convencional (Brachiaria brizantha cv Marandú) & $0,85 \mathrm{c} \mathrm{A*}$ & $0,85 \mathrm{bc} \mathrm{A}$ \\
\hline Eucalipto Clone h13 (E. grandis x E. urophylla) & $0,72 \mathrm{c} \mathrm{A}$ & $0,97 \mathrm{~b} \mathrm{~A}$ \\
\hline Pau-balsa (Ochroma pyramidale) & $1,32 \mathrm{~b} \mathrm{~A}$ & $0,49 \mathrm{~cd} \mathrm{~B}$ \\
\hline Teca (Tectona grandis L. f.) & $0,71 \mathrm{c} \mathrm{A}$ & $0,99 \mathrm{~b} \mathrm{~A}$ \\
\hline Pinho cuiabano (Schizolobium amazonicum Huber ex Ducke) & $0,69 \mathrm{c} \mathrm{A}$ & $0,36 \mathrm{~d}$ B \\
\hline DMS (Tukey 5\%) & 0,4547 & 0,2948 \\
\hline
\end{tabular}

Médias seguidas pela mesma letra minúsculas para colunas e maiúsculas para linhas não diferem estatisticamente entre si, pelo Teste de Tukey, em nível de 5\% de probabilidade.

*Valores duplicados para efeito de comparação com os demais usos 
dos demais tratamentos, fato este que pode ser atribuído ao elevado acúmulo de matéria orgânica do tratamento devido às condições de não ter ocorrido atividade antrópica nesta área, fornecendo, assim, melhores condições para atividade microbiana no solo, corroborando com o resultado observado por Jakelaitis et al. (2008) em área sob vegetação nativa quando comparado a área de pastagem, área de integração lavoura pecuária e área de cultivo agrícola em plantio direto.

Apresentando a menor média da taxa de respiração basal do solo em ambos os locais de avaliação $\left(0,69\right.$ e $0,36 \mathrm{mg}$ de $\mathrm{C}-\mathrm{CO}_{2} \cdot \mathrm{kg}^{-1} \cdot \mathrm{h}^{-1}$, respectivamente para Floresta e pastagem) o tratamento Pinho cuiabano diferiu estatisticamente apenas do uso Mata nativa e Pau-balsa no local Floresta, enquanto que no local Pastagem não diferiu apenas do uso Pau-balsa (Quadro 5). A baixa taxa de respiração basal do solo com o tratamento Pinho cuiabano, que possui em seus folíolos uma relação $\mathrm{C} / \mathrm{N}$ de 2,74 (CARVALHO et al., 2013), pode estar relacionada ao processo de decomposição das folhas e galhos da espécie florestal, que por apresentarem altos teores de nitrogênio em suas composições, exercem influência direta na atividade da microbiota, onde há um maior consumo de Carbono no processo de mineralização do $\mathrm{N}$ (baixa relação $\mathrm{C} / \mathrm{N}$ ). Della Bruna et al. (1991) também verificaram menor atividade microbiana em solos sob áreas de reflorestamento quando comparado com solo sob condições naturais, tendo a composição química do material em decomposição como fator determinante para essa variação.

No local Floresta, o tratamento Pau-balsa apresentou diferença significativa ao local Pastagem, apresentando 1,32 e 0,49 mg de C-CO . $\mathrm{kg}^{-1} \cdot \mathrm{h}^{-1}$ respectivamente, fato esse que pode ser atribuído às características da espécie, a qual, segundo Leão et al. (2008), apresenta rápida formação de copa (sombreamento) e a produção de elevada quantidade de serrapilheira (material orgânico) cria um microclima favorável a atividade microbiana.Este resultado corrobora com os resultados obtido por Melloni et al. (2008), que observaram, em solos sob floresta de Eucalipto implantada em espaçamento de $3 \times 3 \mathrm{~m}$ e em floresta de araucária em espaçamento de $2 \times 2 \mathrm{~m}$, maiores valores de RBS quando comparados à área sob o cultivo de pastagem (Brachiaria decumbens), sendo associado as condições edafoclimáticas dos locais de avalições.

No local Pastagem (Quadro 5), todos os usos diferiram da condição natural, o que pode ter ocorrido devido a maior quantidade de matéria orgânica na condição natural (Quadro 4). Segundo Carmo et al. (2009), em locais com maior densidade de raízes, ocorre maior liberação de compostos exsudados na região rizosférica, contribuindo, assim, com maior fonte de substrato e energia para o metabolismo microbiano.

Os tratamentos Pau-balsa e Pinho cuiabano apresentaram diferenças estatísticas entre os locais de avalições, apresentando no local floresta 0,69 $\mathrm{mg}$ de $\mathrm{C}-\mathrm{CO}_{2} \cdot \mathrm{kg}^{-1} \cdot \mathrm{h}^{-1}$ e no local pastagem $0,36 \mathrm{mg}$ de $\mathrm{C}-\mathrm{CO}_{2} \cdot \mathrm{kg}^{-1} \cdot \mathrm{h}^{-1}$. Silva et al. (2010) caracterizam o conteúdo de água e a temperatura como principais intensificadores de decomposição de material orgânico, que, consequentemente, aumenta a atividade microbiana, resultando na maior emissão de $\mathrm{CO}_{2}$. $\mathrm{Na}$ avaliação em dois períodos do ano (seco e chuvoso), Dias (2008) observou valores semelhantes em solos sob o consórcio de Pinho cuiabano com outras espécies florestais, constatando uma maior atividade microbiana no período chuvoso e menor no período seco, apresentando, respectivamente, média de 0,46 e $0,24 \mathrm{mg}$ de $\mathrm{C}-\mathrm{CO}_{2} \cdot \mathrm{kg}^{-1} \cdot \mathrm{h}^{-1}$.

Os tratamentos Teca, Eucalipto e Pastagem convencional não tiveram diferença significativa entre os locais de avaliações. Pulrolnik et al. (2009) relacionam a baixa atividade microbiana sob material vegetal oriundo do Eucalipto à inferioridade nutricional de seus resíduos (serrapilheira). Segundo Paul e Clark (1996), as condições edafoclimáticas (temperatura, umidade, $\mathrm{pH}$, teores de $\mathrm{O}_{2}$ e de nutrientes no solo) e a qualidade do material orgânico são fatores que exercem grande influência nos resultados da avaliação da RBS em solos sob diferentes manejos e sistemas de produções.

Essas condições podem estar relacionadas aos diferentes comportamentos da RBS em cultivos de Eucalipto, que são observados em diversos trabalhos. Silva et al. (2010) verificaram maiores valores de RBS em solo sob Cerrado nativo, quando 
comparado com solo sob cultivo de Eucalipto de 13 anos. Moraes et al. (2011), em avaliação entre campo nativo e floresta homogênea de Eucalipto, não verificaram diferença significativa. Ibiapina (2011) observou em reflorestamento clonal de Eucalipto de 2 anos de idade valores de RBS superior a área de Cerrado nativo no estado do Piauí. Essas respostas encontradas podem ser um indicativo da grande influência do local e da espécie explorada que contribui para maior ou menor RBS, dependendo muito da época do ano, condições climáticas locais no momento da amostragem e quantidade de serapilheira produzida.

Cunha et al. (2011), Carneiro et al. (2009) e Roscoe et al. (2006) destacam a importância da interpretação dos resultados da atividade biológica, uma vez que elevados valores de respiração nem sempre indicam condições desejáveis: a curto prazo pode significar liberação de nutrientes para as plantas e, a longo prazo, perda de $\mathrm{C}$ orgânico do solo para a atmosfera.

\section{CONCLUSÃO}

- Dentre os sistemas analisados e para as condições em que o estudo foi realizado, apenas os tratamentos Pau-balsa e Teca apresentaram diferença significativa entre os locais de avaliações (no renque florestal e faixa de lavoura/pastagem) na avaliação da RBS;

- O tratamento vegetação nativa apresentou o maior valor Respiração Basal do Solo (RBS), indicando diminuição da atividade microbiana do solo nos outros tratamentos;

- Não houve diferença significativa para os valores de Carbono Orgânico (C-orgânico), e teor de Matéria Orgânica (M.O) para usos e locais de avaliação, indicando a potencialidade dos sistemas para a melhoria da qualidade do solo.

\section{REFERÊNCIAS BIBLIOGRÁFICAS}

ARAÚJO,A.S.F.; MONTEIRO, R.T.R. Indicadores Biológicos de qualidade do solo. Bioscience Journal, Uberlandia, v.23, n.3, p.66-75, 2007.
BAYER, C.; MIELNICZUK, J.; AMADO, T.J.C.; MARTIN-NETO, L.; FERNANDES, S.V. Organic matter storage in a sandy clay loam Acrisol affected by tillage and cropping systems in southern Brazil. Soil and Tillage Research, v.54, n.1-2, p.101-109. 2000 .

BRAZ, S.P.; URQUIAGA, S.; ALVES, B.J.R.; BODDEY, R.M. Degradação de pastagens, matéria orgânica do solo e a recuperação do potencial produtivo em sistemas de baixo "input" tecnológicos na região dos Cerrados. Brasília, EMBRAPA (Circular Técnica, 9) 2004. Disponível em $\quad<$ http://www.infoteca.cnptia.embrapa.br/ bitstream/doc/627822/1/cit009.pdf $>$ Acesso em: 10 jun. 2014.

CARMO, F.F.; BARBOSA, E.A.; SILVA, D.E .; FERNANDES, S.B.; BATISTA, L.M.T.; DINIZ, L.T.; REIS, A.P.; RAMOS, M.L. Avaliação da atividade microbiana em solo do Cerrado sob Sistema de Integração Lavoura Pecuária e culturas anuais. In: CONCRESSO BRASILEIRO DE CIÊNCIA DO SOLO. 32. 2009. Fortaleza. Anais. O solo e a produção de bioenergia: perspectivas e desafios. 2009.

CARNEIRO, M.A.C.; SOUZA, E.D.; REIS, E.F.R.; PEREIRA, H.S.; AZEVEDO, W.R. Atributos físicos, químicos e biológicos de solo de Cerrado sob diferentes sistemas de uso e manejo. Revista Brasileira de Ciência do Solo, Viçosa, v.33, n.1, p.147-157. 2009.

Carvalho, M.; Machado, R.C.; Ahnert, D.; Sodré, G.A.; y do Sacramento, C.K. Avaliação da composição e distribuição mineral em componentes foliares de paricá (Schizolobium amazonicum Huber ex Ducke). Agrotropica, Ilheus, v.25, n.1, p.53-60, 2013.

CHIODEROLI, C.A.; MELLO, L.M.M.; GRIGOLLI, P.J.; FURLANI, C.E.A.; SILVA, J.O.R.; CESARIN, A.L. Atributos físicos do solo e produtividade de soja em sistemas de consórcio milho e braquiária. Revista Brasileira de Engenharia Agrícola e Ambiental, Campina Grande, v.16, n.1, p.37-43, jan. 2012. 
CIOTTA, M.N.; BAYER, C.; ERNANI, P.R.; FONTOURA, S.M.V.; ALBUQUERQUE, J.A.; WOBETO, C. Acidificação de latossolo sob plantio direto. Revista Brasileira de Ciência do Solo, Viçosa, v.26, n.4, p.1055-1064, 2002.

COOPER, M.. Degradação e Recuperação de Solos. Recuperação de Áreas Degradas. ESALQ Piracicaba. 2008. p.31.

CUNHA, E.Q.; STONE, L.F.; FERREIRA; E.P.B.; DIDONET, A.D.; MOREIRA, J.A.A.; LEANDRO, W,M. Sistemas de preparo do solo e culturas de cobertura na produção orgânica de feijão e milho. Revista Brasileira de Ciência do Solo, Viçosa, v.35, n.2, p.603-611. 2011.

DELLA BRUNA, E.; BORGES, A.C.; FERNANDES, B.; BARRO, N.F.; MUCHOVEJ, R.M.C. Atividade da microbiota de solos adicionados de serapilheira de eucalipto e de nutrientes. Revista Brasileira de Ciência do Solo, Viçosa, v.15, n.1, p.15-20. 1991.

DIAS, J.D. Dinâmica do amônio e nitrato em solos consorciados com plantios de paricá (Schizolobium Amazonicum) em Aurora do Pará. 2008. 88p. Dissertação (Mestrado em Ciências Ambientais) - Programa de Pós-Graduação em Ciências Ambientais, Instituto de Geociências, Universidade Federal do Pará, Museu Paraense Emilio Goeldi e EMBRAPA, Belém.

EMPRESA BRASILEIRA DE PESQUISA AGROPECUÁRIA - EMBRAPA. Sistema brasileiro de classificação de solos. 3.ed. Brasília, 2013.353p.

EMBRAPA. Centro Nacional de Pesquisa de Solos. Manual de métodos de análise de solos. 2ed. rev. e atual. Rio de Janeiro: EMBRAPA, 1997, Disponível em $<\underline{\text { http://www.agencia.cnptia. }}$ embrapa.br/Repositorio/Manual+de+Metodos_00 0fzvhotqk02wx5ok0q43a0ram31wtr.pdf> Acesso em: 22 jun. 2014.

FERREIRA, D.F. Sisvar: a computer statistical analysis system. Ciência e Agrotecnologia
(UFLA), v. 35, n.6, p. 1039-1042, 2011.

FERREIRA, J.C.V. Mato Grosso e seus Municípios. Cuiabá - MT: Secretaria de Estado da Educação, 2001, 365p.

FONSECA, G.C.; CARNEIRO, M.A.C.; COSTA, A.R.; OLIVEIRA, G.C.; BALBINO, L.C. Atributos físicos, químicos e biológicos de latossolo vermelho distrófico de Cerrado sob duas rotações de cultura. Revista Pesquisa Agropecuária Tropical, Goiânia, v.37, n.1, p.22-30, 2007.

IBIAPINA, T.V.B. Atributos físicos e biológicos de latossolo amarelo em áreas cultivadas com soja e eucalipto no cerrado Piauiense. 2011. 43p. Dissertação (Mestrado em Agronomia e Produção Vegetal) - Programa de Pós-Graduação em Agronomia/ Produção Vegetal da Universidade Federal do Piaú - UFPI. Teresina. 2011. Disponível em <http://www.ufpi.br/subsiteFiles/ ppga/arquivos/files/dissertacao-\%20thiago.pdf $>$. Acesso em: 11 jun. 2014.

JAKELAITIS, A.; SILVA, A.A.; SANTOS, J.B.; VIVIAN, R. Qualidade da camada superficial de solo sob mata, pastagens e áreas cultivadas. Revista Pesquisa Agropecuária Tropical, Goiânia, v.38, n.2, p.118-127, 2008.

JENKINSON, D.S.; LADD, J.N. Microbial biomass in soil: measurement and turnover. In: PAUL, E.A. \& LADD, J.N., eds., Soil Biology \& Biochemistry, v.5, p.415-471, 1981.

MACEDO, M.C.M. Integração lavoura e pecuária: o estado da arte e inovações tecnológicas. Revista Brasileira de Zootecnia, Viçosa, v.38, no.spe, p.133-146, jul. 2009.

LEÃO, N.V.M.; FREITAS, A.D.D.; CARRERA, R. Pau-de-balsa Ochroma pyramidale (Cav. ex Lamb.) Urban. Informativo Técnico - Rede de Sementes da Amazônia. 2008. Disponível em $<$ https://www.inpa.gov.br/sementes/iT/19_Pau-debalsa.pdf> Acesso em: 7 ago. 2015.

MELLONI, R.; MELLONI, E.G.P.; ALVARENGA, 
M.I.N. ; VIEIRA, F.B.M. Avaliação da qualidade de solos sob diferentes coberturas florestais e de pastagem no sul de Minas Gerais. Revista Brasileira de Ciência do Solo, v.32, p.2461-2470, 2008.

MELO, J.T.; RESCK, D.V.S. Retorno ao solo de nutrientes de serrapilheira de Eucalyptus camaldulensis no Cerrado do Distrito Federal. Boletim de pesquisa e desenvolvimento - Embrapa - Cerrados, 17 p.2003.

MORAES, J.R.; CASTILHOS, D.D.; PINTO, L.F.S.; OLDRA. S.; DA ROSA, D.S.B.; CASTILHO, R.M.V. Atributos microbiológicos em solos sob campo nativo e cultivados com eucalipto no Bioma Pampa. IN: XIII Encontro de Pós-Graduação-UFPEL. Anais. Pelotas - RS. 2011. Disponível em <http://www2.ufpel.edu.br/ enpos/2011/anais/pdf/CA/CA_00284.pdf> Acesso em: 10 jun. 2014.

NETTO, I.T.P.; KATO, E.; GOEDERT, W.J. Atributos físicos e químicos de um latosssolo vermelho-amarelo sob pastagem com diferentes tipos de usos. Revista Brasileira de Ciência do Solo, Viçosa, v.33, n.5. p.1441-1448, 2009.

NEVES, C.M.N.; SILVA, M.L.N.; CURI, N.; MACEDO, R.L.G.; MOREIRA, F.M.S.; D'ANDRÉA, A.F. Indicadores da qualidade do solo em sistema agrossilvopastoril no noroeste do Estado de Minas Gerais. Ciências Agrotécnicas, Lavras, v.33, n.1, p.105-112, 2009.

PAUL, E.A.; CLARK, F.E. Dynamics of residue decomposition and soil organic matter turnover. In: Soil Microbiology and Biochemistry. 2nd ed. San Diego: Academic. 1996.

PEREIRA, A.A.; HUNGRIA, M.; FRANCHINI, J.C.; KASCHUK, G.; CHUEIRE, L.M.O.; CAMPO, R.J.; TORRES, E. Variações qualitativas e quantitativas na microbiota do solo e na fixação biológica do nitrogênio sob diferentes manejos com soja. Revista Brasileira de Ciência do Solo, Viçosa, v.31, n.6, p.1397-1412, 2007.
PULROLNIK, K.; BARROS, N.F.; SILVA, I.R.; NOVAIS, R.F.; BRANDANI, C.B. Estoques de carbono e nitrogênio em frações lábeis e estáveis da matéria orgânica de solos sob eucalipto, pastagem e cerrado no Vale do Jequitinhonha - MG. Revista Brasileira de Ciência do Solo, Viçosa, v.33, n.5, p.1125-1136. 2009.

ROSCOE, R.; MARCANTE. F.M.; SALTON, J.C. Dinâmica da matéria orgânica do solo em sistemas conservacionistas: modelagem matemática e métodos auxiliares. Dourados: Embrapa Agropecuária Oeste, 304p.:Il. 2006. Disponível em $<$ http://docsagencia.cnptia. embrapa.br/agriculturaOrganica/Sistemas Manejo Materia_Organica.pdf $>$ Acesso em: 02 jun. 2014.

SANTOS, H.P.; FONTANELLI, R.S.; SPERA, S.T.; TOMM, G.O. Efeitos de sistemas de produção integração lavoura-pecuaria (ILP) sobre a fertilidade do solo em plantio direto. Acta Scientiarum Agronomy, Maringá, v.31, n.4, p.719-727. 2009.

SILVA, E.E.; AZEVEDO, P.H.S.; DE-POLLI, H. Determinação da respiração basal (RBS) e quociente metabólico do solo $\left(\mathrm{qCO}_{2}\right)$. Comunicado Técnico 99. Embrapa. Seropédica - RJ. 2007. Disponível em $<$ http://www.infoteca.cnptia. embrapa.br/bitstream/doc/627577/1/cot099.pdf> Acesso em: 19 jun. 2014.

SILVA, R.R.; SILVA, M.L.N.; CARDOSO, E.L.; MOREIRA, F.M.S.; CURI, N.; ALOVISI, A.M.T. Biomassa e atividade microbiana em solo sob diferentes sistemas de manejo na região fisiográfica Campos das Vertentes - MG. Revista Brasileira de Ciência do Solo, Viçosa, v.34, n.5, p.15851592, 2010.

SILVA, W.M.; CREMON, C.; MAPELI, N.C.; FERRI, M.; MAGALHÃES, W.A.; Atividade microbiana e decomposição de diferentes resíduos orgânicos em um solo sob condições de campo e estresse hídrico simulado. Agrarian, Dourados, v.2, n.6, p.33-46, 2010. 